\title{
UMA LEITURA CRÍTICA DA SITUAÇÃO DO IDOSO NO ATUAL CONTEXTO SOCIOCULTURAL
}

\section{Resumo}

José Roque Junges ${ }^{1}$

$\mathrm{O}$ artigo faz uma crítica cultural da mentalidade subjacente à situação do idoso no atual contexto socio-cultural pós-moderno, tendo como referência as análises de A. Gorz sobre a sociedade do trabalho Assalariado e as de L. Sfez sobre a Ideologia da Saúde Perfeita. Levanta alguns aspectos antropológicos, implicados no processo de envelhecimento, a partir da antropologia filosófica de H. C. de L. Vaz. Aponta para os quatro tradicionais princípios bioéticos - autonomia, beneficência, não-maleficência e justiça na sua relevância para o cuidado do idoso.

Palavras-chave: Idoso. Envelhecimento. Mentalidade Cultural. Contexto Sociocultural Pós-moderno. Antropologia da Senectude. Bioética da Ancianidade.

\section{Introdução}

Para Beauvoir (1976) existe uma dificuldade na cultura moderna em abordar a questão do idoso. A velhice é um assunto vergonhoso do qual é indecente falar. Trata-se de um tabu que é melhor esquecer, por ser um assunto que incomoda. Vive-se uma contradição entre a busca de uma sempre maior longevidade e uma crescente situação de marginalização e obsolescência do idoso. Constata-se que, por um lado, a ciência busca a realização do sonho da imortalidade mas, por outro, a economia aponta para a inutilidade do idoso reduzido à sua condição de puro consumidor de produtos que prometem longevidade.

Em todos os países desenvolvidos e em desenvolvimento a expectativa de vida aumentou consideravelmente no último século. Em 2000 a expectativa de vida no Brasil era de 64,8 anos para os homens e 72,5 para as mulheres. Em 20 anos a estimativa de vida dos brasileiros aumentou 7,6 anos para os homens e 8,2 para as mulheres. Se em 1940 a participação da população

* Formação em Filosofia, História e Teologia. Doutorado em Teologia Moral. Professor de Antropologia da saúde e Bioética no PPG de Ciências da Saúde - Área de Concentração Saúde Coletiva. Universidade do Vale do Rio dos Sinos (UNISINOS). E-mail: roque@bios.unisinos.br 
com mais de 65 anos era de 2,4\%, em 2000 era de 5,8\%. As últimas projeções indicam que esse segmento será de $15 \%$ da população no ano de 2020 . O aumento de longevidade é causado pela melhoria dos níveis de nutrição e dos serviços de saúde.

A esse crescimento da estimativa de vida não correspondeu uma valorização social das pessoas idosas. Elas são sempre mais vistas como um estorvo para as famílias e fator de gastos previdenciários. A geriatria e a gerontologia (MORAGAS, 1997) preocupam-se em alongar quantitativamente e melhorar qualitativamente a vida dos idosos, mas a mentalidade sócio-cultural que valoriza o ideal da juventude e as estruturas político-econômicas que favorecem a utilidade social das pessoas não sabem bem o que fazer com os idosos sempre mais presentes no cenário social.

Se, numa situação abastada, a presença do idoso é um problema e motivo de preocupação, na família pobre de periferia o idoso é disputado, porque é um fator de ingresso de renda e em alguns casos o único sustento da família por meio da parca aposentadoria. Por outro lado, a mulher idosa exerce um papel importante no cuidado da casa e dos netos, enquanto os outros membros adultos trabalham fora. Nesse sentido o idoso pobre pode passar necessidade por ter uma aposentadoria insignificante, mas, por outro lado, sente-se valorizado e útil ao convívio familiar. Mas essa valorização pode também ser interesseira, engendrando relações patológicas de manipulação e aproveitamento em detrimento do bem estar do idoso.

Assim a ancianidade é, por um lado, uma questão demográfica e gerontológica que aponta para uma crescente melhoria quantitativa e qualitativa da vida dos idosos e, por outro, é uma questão sócio-cultural e econômica que não se sabe como lidar, porque incomoda e cria mal-estar. O problema ético de fundo da situação do idoso tem sua origem nessa esquizofrenia e contradição entre valorização e desvalorização da senectude. A causa dessa esquizofrenia está na crise do paradigma cultural que sustenta a sociedade atual.

\section{Crise da Sociedade do Trabalho Assalariado}

Para Gorz (1997) e Pochmann (2001), a sociedade do trabalho é aquela em que as pessoas são definidas na sua cidadania pelo trabalho assalariado que possuem. Essa compreensão está em crise pela sempre maior precarização dos empregos e um crescente aumento do trabalho informal. 
Existe um processo de desassalariamento, isto é, redução relativa da participação dos assalariados no total da ocupação. Hoje os assalariados perdem, no cômputo geral, para os desempregados ou precariamente ocupados. O trabalho informal ocupa um lugar sempre mais importante na produção econômica. Essa precarização do trabalho assalariado pela flexibilização das leis trabalhistas faz parte do atual processo de acumulação e globalização do capital.

Nessa sociedade do trabalho as pessoas conseguem seu sustento pelo salário que recebem de um emprego. Mas se o emprego está em constante fragilização e precarização, a condição de trabalhador, empregado ou assalariado, está aos poucos se extinguindo e o salário como meio de sobrevivência e vida digna, ideado pela sociedade industrializada moderna, está em crise. A sociedade do trabalho assalariado está desaparecendo sem substituí-la por nenhuma outra. Esse contexto cria uma situação desumana e cruel porque precariza sempre mais o salário como meio de sustento e não cria nada para substituir o estratagema culturalmente consagrado de angariar meios para a sobrevivência. Portanto, a relação entre salário e reprodução da vida está em crise, sendo necessário encontrar outros caminhos de sustentabilidade econômica dos indivíduos.

Outra relação típica da sociedade industrializada moderna é a vinculação entre trabalho e emprego. Até pouco tempo atrás só era reconhecido socialmente como trabalhador quem tinha emprego. Essa identificação cria uma falsa compreensão de trabalho. Um exemplo são os afazeres domésticos não considerados como trabalho mas prendas do lar. A crise da sociedade de trabalho assalariado obriga a repensar o sentido e a organização do trabalho. O ser humano realiza-se no trabalho que, não necessariamente e sempre menos, identifica-se com emprego. Mas como a sociedade industrial moderna criou uma concepção cultural da estreita relação entre trabalho e emprego/salário, as pessoas concebem, como válido, o trabalho assalariado.

Muitos propõem a diminuição da jornada de trabalho sem redução salarial como uma solução para o desemprego. Certamente é um caminho de solução. Mas não resolve a questão em sua totalidade, porque o emprego pleno não será mais possível, devido às inovações tecnológicas que dispensam mão de obra. Assim sobrará sempre mais tempo livre em que as pessoas podem dedicar-se a atividades de lazer e de arte ou assumir um trabalho comunitário de voluntariado sem vínculo empregatício. Dessa maneira o 
trabalho seria desempenhado com prazer e criatividade e seria um meio de estabelecer laços sociais e trocas baseadas no dom.

Por outro lado, é necessário encontrar uma outra solução para a questão da sustentabilidade e reprodução da vida das pessoas, não mais unicamente pelo caminho do salário, pois o trabalho assalariado está em progressiva diminuição. Alguns estão propondo o chamado mínimo vital que seria o direito a um salário vital, isto é, uma quantia de dinheiro necessária para uma vida digna, enquanto ser humano ou cidadão, independente de ter um trabalho assalariado ou não. Por isso, inspirando-se nas reflexões de Mauss (1924) e Caillé (2002) pode-se dizer que só haverá uma solução para a crise da sociedade do trabalho assalariado, quando a economia do mercado, movida pelo interesse, for corrigida e completada pela economia do dom, movida pela troca simbólica.

Em que essa análise do fim da sociedade do trabalho assalariado ajuda a entender a situação do idoso? O mal estar em relação ao idoso vem justamente da cultura que sustenta a compreensão e a vivência do trabalho assalariado. A aposentadoria é concebida e calculada em relação ao salário. A crescente precarização do salário tem sua história de efeitos sobre a própria aposentadoria. A insatisfação em relação às aposentadorias é conseqüência da fragilização do sistema salarial.

A identificação entre trabalho e emprego leva a que o aposentado se sinta inútil já que não consegue mais ser aceito num trabalho com vínculo empregatício e, portanto, receber salário. Na mentalidade atual, o trabalho assalariado é socialmente reconhecido. Só a pessoa com emprego é reconhecida como útil para a sociedade. Essa compreensão cria uma consciência de inutilidade e obsolescência no aposentado. Essa consciência cresce com o aparecimento dos achaques da velhice e na medida em que the é conferido o papel reconhecido de aposentado/idoso que engloba o direito de não trabalhar e receber a assistência social.

Com a crise da sociedade do trabalho assalariado e a conseqüente precarização da vinculação entre trabalho e emprego, torna-se possível superar a visão redutora do trabalho, abrindo-se a perspectiva cultural de o aposentado/idoso trabalhar e sentir-se útil para a comunidade. Para isso, contudo, é necessário uma revolução cultural na compreensão do trabalho e na organização do acesso aos meios para levar uma vida digna. 


\section{Ideologia da Saúde Perfeita}

A crise do trabalho assalariado por si só não explica a esquizofrenia que vive a sociedade atual em relação ao idoso. A ideologia cultural, idealizando o jovem como paradigma do ser humano, apresenta a pessoa sem nenhum defeito e com saúde perfeita como critério de felicidade.

A década de 90 foi apresentada como o fim da história e o ocaso das utopias. As pessoas teriam deixado de sonhar e lutariam apenas pelo bem estar do presente. O futuro não seria mais um pólo mobilizador da atividade humana. O que interessaria seria o momento presente na sua realidade sensível. O futuro caracterizar-se-ia pela irrealidade e a incerteza. Por isso, as utopias não impulsionariam mais a ação nem arrastariam mais os grupos que lutam por um projeto. A queda do muro de Berlim e o fracasso do socialismo real seriam a prova desse estado de espírito. O marxismo teria deixado de ser a utopia de mobilização popular. Os operários lutariam por melhores condições de bem-estar no presente e não estariam interessados em ser protagonistas de uma sociedade futura sem classes e sem opressão.

Sfez (1996) procura mostrar, através de fatos, documentos e análise cultural, que as utopias não acabaram, apenas mudaram de figura. As formas simbólicas da política e da comunicação como utopias sociais exauriram sua capacidade de mobilização cultural. Hoje desponta uma nova utopia em sua roupagem não mais política nem comunicacional, mas sanitária, prometendo uma saúde perfeita e elevando a medicina ao papel de ciência que promete a realização de um mundo sem males e sem dor. As promessas do progresso da medicina, possibilitadas principalmente pelo projeto de seqüenciamento do genoma humano, correspondem justamente a essa pretensão de concretizar a utopia da saúde perfeita. O genoma é o novo "Santo Graal" que promete o elixir da eterna juventude.

Quais são as implicações dessa ideologia cultural para a compreensão e vivência do idoso? Os progressos da medicina possibilitaram um crescente aumento da longevidade do ser humano e melhoraram sensivelmente a saúde física das pessoas de mais idade. Esses resultados despertam sempre maiores expectativas de melhorar indefinidamente a situação do idoso e acalentam o sonho de alcançar a imortalidade física. É louvável e promissor a crescente melhoria quantitativa e qualitativa da qualidade de vida do idoso, mas é questionável uma ideologia cultural que cria mistificações simbólicas e sustenta 
falsas esperanças em relação à ancianidade.

Os valores que a cultura atual favorece dificultam a vivência do processo de envelhecimento. Essa dificuldade leva a desenvolver sucedâneos e a criar tabus que eludem a realidade da senectude. Faz parte de uma velhice sadia a aceitação tranqüila das deficiências e fraquezas inevitáveis que a longevidade impõe e a conseqüente reconciliação pacífica com a perspectiva da morte. Mas a cultura atual, movida pela utopia da saúde perfeita, não consegue oferecer recursos simbólicos que ajudem a essa integração sadia da ancianidade.

Num mundo sanitariamente perfeito, a velhice é transformada em doença que precisa ser debelada. Não existe lugar reconhecido para os idosos porque estes não correspondem ao ideal de pessoa em perfeitas condições. Eles são recolhidos nos asilos e clínicas, porque são um estorvo num mundo organizado para a produtividade. São escondidos do convívio porque estampam, no seu rosto, as rugas da velhice que incomodam o estereótipo cultural da eterna juventude. A figura do idoso questiona a idealização atual do jovem, porque lembra inconscientemente a esse que ele será um dia o que o ancião é hoje. Essa lembrança é indecente para a cultura atual. Por isso é melhor esquecê-la e não falar dela. Nessa situação cultural, o idoso não tem um lugar nem um papel social reconhecidos.

\section{Significado Antropológico do Processo de Envelhecimento}

Os progressos da geriatria em aumentar a longevidade e melhorar a qualidade de vida dos idosos levou a uma compreensão da velhice a partir da metáfora terapêutica. Esse fato de conseqüências positivas, porém reforçado culturalmente pela ideologia da saúde perfeita, provocou uma crescente medicalização da ancianidade, considerada como uma doença a ser curada. Assim a velhice tornou-se predominantemente um fato biológico, esquecendo a sua dimensão antropológico-existencial. (LOLAS STEPKE, 2000). A senectude é antes de mais nada um fato biográfico. O biológico só adquire significado humano, quando integrado nesse horizonte mais amplo do itinerário historico-existencial do idoso. Por isso é necessário recuperar a ancianidade como evento pessoal e explicitar o significado antropológico do processo de envelhecimento. A senescência recorda e expressa constantes antropológicas típicas do ser humano e importantes para sua felicidade, mas que podem passar desapercebidas pela vitalidade que se experimenta na idade juvenil. 


\subsection{Consciência da Vulnerabilidade}

Uma das primeiras percepções do processo de envelhecimento é a consciência da vulnerabilidade. A pessoa começa a dar-se conta que não tem mais a energia e a vitalidade de antes, sendo, por isso, mais vulnerável e frágil diante de fatores biológicos ou psicológicos tendentes ao desequilíbrio. Se a pessoa sempre se considerou forte e independente, não aceitando em si os efeitos da fragilidade, essa consciência da vulnerabilidade será motivo de incômodo e de reação. Mas o processo de senescência é inexorável, mostrando pouco a pouco seus efeitos. Se a pessoa não aprende a integrar esses efeitos inevitáveis, chegando a um equilíbrio vital e psicológico condizente com a nova situação existencial terá dificuldade em aceitar a velhice, considerada pesada e incômoda. Daí a importância de integrar a vulnerabilidade como uma nota característica da existência humana.

A modernidade colocou tal poder de intervenção nas mãos do ser humano para superar determinismos que criou uma consciência demiúrgica de onipotência e um conseqüente esquecimento da radical vulnerabilidade do ser humano. O jovem é o ícone dessa consciência considerado por isso mesmo ideal de ser humano, enquanto que o idoso relembra justamente a vulnerabilidade a ser superada. Esse olvido está na causa da crise ética e do vazio de sentido que vivem a mentalidade atual.

Viver humanamente é viver em vulnerabilidade. (TORRALBA i ROSELLÓ, 1998). Por ser pluridimensional e inter-relacional o ser humano não se basta a si mesmo, porque necessita construir sua unidade estrutural e relacional em abertura aos outros e à realidade que o circunda. Essa unidade nunca está acabada e constantemente ameaçada por elementos próprios e alheios que a desestruturam. O ser humano é vulnerável não só no aspecto somático, mas também psíquico, social e espiritual. Hoje sentem-se, sempre menos, os efeitos somáticos da vulnerabilidade devido aos progressos das ciências da saúde. Mas ela é sempre mais visível na sua face social, psíquica e espiritual, crescente causa de sofrimento e dor para muita gente. Os referenciais culturais não ajudam a integrar essa vulnerabilidade, mas, ao contrário, a negam oferecendo próteses e placebos de sentido.

O ser humano é mais vulnerável que outros seres vivos por sua pluridimensionalidade, embora seja mais hábil em proteger-se por sua condição cultural. Ele não só é vulnerável, mas pode tornar-se consciente dessa 
vulnerabilidade. Pode refletir sobre ela, criando referências culturais para integrá-la ou contestá-la. A fragilidade do recém-nascido humano, diferentemente do filhote de animal, é a própria expressão dessa vulnerabilidade. Mas ela é uma fragilidade que será aos poucos superada. $\mathrm{O}$ velho, ao contrário, é o próprio rosto que estampa a vulnerabilidade inevitável. Por isso a velhice é um assunto indecente que incomoda à cultura atual. Essa renega e repudia o significado e os efeitos da vulnerabilidade radical do ser humano. A presença do ancião relembra continuamente essa constante antropológica.

\subsection{Temporalidade como Condição Humana}

A enfermidade é a própria metáfora da vulnerabilidade; o sofrimento é o rosto amargo dessa experiência. São realidades que podem acometer o ser humano, mas não são permanentes. A temporalidade e a morte fazem parte da condição permanente do ser humano enquanto vulnerável. A consciência da vulnerabilidade aparece na velhice porque o idoso se dá conta do passar do tempo e da proximidade da morte. Essas duas condições são constantes antropológicas típicas do ser humano.

A condição temporal está belamente expressa em um texto da pensadora feminista Ivone Gebara:

A vida vai deixado através do corpo suas marcas, vai desenhando traços firmes que contornam os rostos abrindo sulcos, como marcas indeléveis que se multiplicam e se acentuam ao longo dos anos. Vai embranquecendo e rarefazendo os cabelos, vai fazendo o corpo sentir os anos passarem inexoravelmente. A vida vai escrevendo nossa história em nosso próprio corpo, em nossos gestos, em nosso olhar. Os caminhos percorridos, os anos vividos, as alegrias e sofrimentos, as esperanças, os desejos escondidos parecem confluir todos para o mesmo corpo, agora capaz de revelar uma história, capaz de deixar as rugas falarem, porque elas têm de fato uma história. O rosto envelhecido é história, permite uma interpretação, provoca interpretações, faz pensar... Envelhecer é perceber esse passar da vida, constante e intenso, como se a gente pudesse se olhar no espelho e, em um minuto, ver a metamorfose do mesmo rosto desfilando sucessivamente diante dos próprios olhos, transformando-se gradativamente de jovem para velho. (GEBARA, 1991, p. 109). 
A temporalidade expressa ao mesmo tempo fugacidade (dimensão cronológica) e oportunidade (dimensão cairológica). O tempo, por um lado, faz tudo passar pelo crivo do processo cronológico da decrepitude e caducidade que leva ao desgaste e à destruição, mas, por outro, é ocasião oportuna do aparecimento do novo pela criação e renovação da identidade. A evolução, por ser atravessada pela flecha do tempo, é ao mesmo tempo morte e vida como duas faces do mesmo fenômeno.

Se as duas dimensões do tempo fazem parte da própria evolução dos seres vivos, a temporalidade cronológica e cairológica adquirem nos seres humanos um significado especial. O tempo humano é experimentado cronologicamente na velhice como um tempo passado que não volta atrás; como senilidade expressa-se no aparecimento das rugas do rosto, na decrepitude da energia corporal e na certeza da morte. Ao mesmo tempo, no entanto, significa acumulo de experiência pessoal e construção de história que são oportunidades que ajudam a enfrentar o futuro.

O tempo cronológico compreende o presente a partir do passado, isto é, olha para trás para dar-se conta, no momento atual, do tempo que já passou, enquanto que o tempo cairológico, olha para a frente, para as oportunidades de futuro que se abrem para o novo que poderá despontar. A cultura atual incentiva e preza somente a imediatidade do presente sem referência ao passado ou ao futuro. O que importa é o momento presente com suas ocasiões de prazer e felicidade. O passado lembra a fugacidade do tempo com suas marcas que é melhor esquecer, não tendo nada a oferecer como referencial. O futuro é o incerto ainda a ser construído, necessitando esforço e engajamento que não vale a pena despender. Sendo assim a mentalidade atual reduz a temporalidade ao presente cronológico e a esvazia de seu significado antropológico, tentando esquecer e negar a fugacidade do tempo, expressa no passado, e a sua oportunidade, manifesta na abertura ao futuro. O processo de envelhecimento obriga a enfrentar-se com a dimensão cronológica e cairológica da temporalidade humana.

\subsection{A Morte como Condição Humana}

A temporalidade aponta para outra constante antropológica que é a condição mortal. O ser humano é um ser-para-a-morte. Todos os seres vivos são voltados à morte. $\mathrm{O}$ processo de morte faz parte do surgimento da vida. 
Para viver é preciso continuamente morrer. Isso tem, nos humanos, um significado somático, mas também psíquico-espiritual. O corpo está em contínua reorganização pela morte e renovação de células até o momento em que essa autopoiese não seja mais possível, sobrevindo a morte total. Por ter consciência da sua condição mortal, o ser humano precisa enfrentar-se existencialmente com ela. A morte é um desafio psíco-espiritual para o qual é necessário encontrar um sentido. Todas as culturas armazenaram, em suas religiões, referenciais para esse sentido, capacitando os seres humanos a enfrentar a fatalidade da morte.

A cultura moderna, sempre mais secularizada, procura eludir a questão, tornando a morte um tabu. Se, antes, o sexo era um tabu cultural, hoje a morte ocupa o seu lugar. Antes o sexo era uma realidade sobre o qual não se falava, com o qual não se tinha uma relação de naturalidade, sendo um tema proibido. Hoje, ao contrário, o sexo é um tema exposto em público com a maior naturalidade, sem tabus. Antes havia uma convivência quotidiana com a morte, porque ela fazia parte do dia a dia das pessoas, sendo enfrentada com naturalidade e sem velamentos. O momento da morte acontecia no próprio lar com acompanhamento dos familiares, onde também aconteciam os ritos fúnebres. Hoje, ao contrário, a morte acontece em geral na solidão hospitalar. Sua expressão é considerada vergonhosa e indecente, sendo escondida e velada em lugares apropriados para reduzir sua manifestação. A morte tornouse um tema tabu do qual é sempre mais difícil falar. Os próprios ritos fúnebres, que hoje acompanham o momento final, apontam para essa tabuização.

O processo de envelhecimento não pode querer eludir a questão da morte por ser uma condição permanente do ser humano da qual ele começa a dar-se conta e a defrontar-se mais claramente, quando se inicia a ancianidade. Faz parte da arte de envelhecer com dignidade saber incluir, com paz e com sentido, a morte no horizonte mais imediato da vida. Mas a mentalidade e a cultura hodierna não oferecem referenciais espirituais para integrar essa realidade, porque a morte é um tema tabu. Essa falta aponta para a própria crise de sentido que vive a sociedade atual. A presença do idoso relembra a todos essa constante antropológica que não pode ser esquecida por fazer parte da vida verdadeira, mas que se procura eludir com placebos culturais.

\section{Dimensões Antropológicas da Senescência}

Como se preparar durante a vida para tirar proveito da velhice? Saber 
envelhecer com dignidade é uma tarefa que cabe a cada ser humano. $\mathrm{O}$ modo de defrontar-se com a velhice depende muito da maneira como a pessoa enfrentou a vida. Trata-se de uma tarefa que atualmente é de responsabilidade exclusivamente individual. Na sociedade moderna é geralmente no momento da aposentadoria que a pessoa se defronta com a tarefa de resituar a sua vida e pensar o que fazer de agora em diante. Esse fato a obriga a refletir sobre a nova fase da vida que se abre: a senectude. Nas culturas tradicionais essa tarefa era facilitada, porque não existia um corte brusco no cotidiano como acontece hoje com a aposentadoria compulsória. Por outro lado, o papel do idoso era socialmente reconhecido e apreciado no seu grupo de pertença comunitária, o que hoje não é o caso. Constata-se um vazio cultural em relação à ancianidade no atual contexto sócio-cultural, impondo sempre mais a urgência de pensar em políticas públicas que facilitem essa tarefa.

Para refletir sobre a tarefa existencial de defrontar-se com a ancianidade é importante ter presente as dimensões do processo de envelhecimento. Essas dimensões correspondem àquelas de qualquer outra experiência humana autêntica. $\mathrm{O}$ ser humano caracteriza-se pelas estruturas de corpo, psique e espírito como diferentes dimensões de sua unidade existencial que é sempre situada sócio-culturalmente. Assim qualquer experiência, definida como humana, terá sempre as três dimensões: somática, psíquica e espiritual, inseridas e vividas num determinado contexto. O processo da senescência, como experiência humana, será também pervadido por essas três dimensões. A compreensão e explicitação das dimensões seguirá a perspectiva da antropologia filosófica de Vaz (1991-1992).

\subsection{Dimensão Somática: o corpo}

As primeiras manifestações do envelhecimento aparecem no corpo: rugas no rosto, flacidez nos músculos, embranquecimento e/ou perda do cabelo, diminuição da energia física etc. Existem várias teorias que tentam explicar essa transformação somática. Para a teoria do dano primário, o envelhecimento é devido a um dano provocado por agentes tóxicos presentes no organismo e no ambiente. O mais citado desse agentes são os radicais livres presentes no oxigênio absorvido pelo sangue que provocam alterações profundas no metabolismo da célula ao nível das mitocôndrias. Outras teorias são de cunho mais genético, colocando a causa da senescência nos genes, especialmente nos telômeros dos cromossomas. O fator chave da 
sobrevivência e, conseqüentemente, da longevidade do organismo está na habilidade das células em resistir, adaptar e reparar moléculas danificadas. (MARTIN; BAKER, 1995; PETRINI,1999).

A característica fundamental da vida é a autopoiese (MATURANA; VARELA, 1997) que permite que os seres vivos se auto-organizem continuamente para sobreviver. O envelhecimento significará a gradativa diminuição e a morte, a perda definitiva da capacidade de autopoiese. Nos seres humanos essa capacidade adquire uma maior complexificação por ela ser acrescida de elementos culturais.

O corpo não é apenas uma realidade biológica; é um evento pessoal e cultural. A dimensão corporal do ser humano não se reduz à sua estrutura físico-material pois se expressa, fundamentalmente, como "corpo próprio". Este compreende a apropriação da realidade corporal como expressão de si mesmo, manifestada, por exemplo, no esquematismo corporal. Nesse sentido, o "corpo próprio" é a configuração pessoal da estrutura somática assumida como sujeito. A pessoa tem auto-consciência e revela-se aos outros através do seu corpo apropriado como manifestação de si. Essa apropriação depende de formas culturais que significam o corpo em determinado contexto.

Essa reflexão antropológica sobre o "corpo próprio" tem um significado transcendental para o processo de envelhecimento. Se o corpo biológico sofre fragilização e decrepitude, o "corpo próprio" é algo adquirido que faz parte da identidade do sujeito, dependendo mais da experiência pessoal com sua estrutura somática do que da fisiologia. Além do mais o corpo está enriquecido pelas marcas de uma história existencial que identificam o idoso. Existe uma beleza e um encantamento paradoxais num rosto enrugado pelo tempo, numa mão encarquilhada pelo trabalho, num corpo curtido nos embates da vida. Daí a importância de trabalhar a consciência do eu corporal para fazer frente ao debilitamento físico e aos achaques fisiológicos que se manifestam. Uma sadia apropriação do corpo como expressão de si ajuda a cuidar e assumir atitudes dietéticas e fisioterápicas necessárias a uma boa forma física do idoso.

\subsection{Dimensão Psíquica: a psique}

O ser humano não é apenas exterioridade somática, mas também interioridade psíquica. $\mathrm{O}$ eu interior configura-se pela imaginação e pela afetividade. É constituído de representações e de desejos que conformam o 
seu conteúdo. Pela imaginação entram representações que vem fora e, ao nível da afetividade, emergem desejos que vão conformando a psique. Eles incluem elementos tanto conscientes e quanto inconscientes que vão traçando a psicografia interior da pessoa .

O corpo é uma realidade imediata, isto é, os outros tem acesso sem mediações ao corpo. A interioridade, ao contrário, não é imediata, porque os outros só podem aceder ao eu interior mediado pelo próprio sujeito. Os outros podem conhecer a vivência psíquica de alguém, se ele abrir a sua interioridade. A abertura à realidade faz suscitar as representações e os desejos que são o conteúdo e o combustível da interioridade. O eu interior configurase essencialmente na relação com os outros. Daí a importância da intersubjetividade para uma conformação sadia da psique, apontando para os distúrbios psicológicos manifestados no autismo e narcisismo. Assim, na relação, a pessoa vai apropriando-se e assumindo sua estrutura psíquica como sujeito.

Se essa é a estrutura antropológica da psique humana, podemos imaginar o seu significado profundo no processo do envelhecimento. Devido ao debilitamento da energia física e ao maior tempo ocioso disponível, o idoso viverá com mais intensidade sua interioridade, suscitando representações e desejos. Por isso a ancianidade é carregada de maior sensibilidade afetiva e memória representativa. Na velhice as pessoas estão mais propensas a manifestar sentimentos e a recordar fatos do passado. A interioridade psíquica manifesta-se mais devido a uma fragilização dos controles e a uma menor preocupação com as máscaras da exterioridade corporal já debilitada.

Com uma maior exposição de sua interioridade, o idoso põe para fora as luzes e as sombras que habitam o seu coração. Aquelas realidades interiores, positivas ou negativas, que antes eram levadas com certa consciência e controle, diluindo-se no quotidiano dos afazeres da vida, agora emergem na sua espontaneidade com menor recurso a racionalizações. Tanto o velho como a criança vivem com menos máscaras, porque estão menos preocupados com sua imagem. Mostram aquilo que são. Na velhice manifesta-se o que a pessoa conseguiu viver de valor e desvalor em sua vida. As virtudes reluzem mais diáfanas e os defeitos aparecem com mais intensidade devido a uma maior exposição de sua interioridade. Nesse sentido existe, na ancianidade, uma diminuição da privacidade como conseqüência da maior vulnerabilidade e necessidade da presença e do cuidado de outros. 


\subsection{Dimensão Espiritual: o espírito}

O ser humano não se reduz à sua exterioridade somática expressa no corpo nem à sua interioridade psíquica, pois ele também se caracteriza pela dimensão espiritual que está além da realidade da psique. Ao nível do espírito o ser humano busca um significado para o seu agir, para a sua existência que move a busca da auto-realização e da felicidade. Esse significado manifestase como um horizonte de sentido que transcende a pura factualidade da existência e a própria interioridade psíquica. O sentido revela-se como um absoluto que sobrepassa a relatividade do cotidiano, não sendo algo que o ser humano constrói para si, mas uma realidade a ser buscada e descoberta no além da imediatidade da vida. O sentido revela-se ao sujeito como algo que arrasta e inspira, dando novos olhos para ver a realidade circundante e energia renovada para enfrentar os embates da vida.

A humanidade sempre soube responder, em sua cultura, aos apelos do espírito humano. As diferentes religiões foram a máxima expressão dessa busca de resposta pelo sentido da vida. A história demonstra essa centralidade da religião nas diferentes culturas. Ela é o próprio núcleo da simbólica cultural. Mas a tendência secularizante da cultura moderna alijou sempre mais a religião da cultura, introduzindo um materialismo que reduz o ser humano à sua estrutura somática e psíquica, negando a sua dimensão de transcendência. A crise civilizacional que assistimos é provocado por essa impossibilidade de a cultura moderna propor referenciais absolutos de sentido. Esse é buscado na imanência das ofertas da técnica e na imediatidade dos apelos do presente, esvaziando-o de sua perspectiva de horizonte que transcende o puro dado. Hoje as pessoas encontram escassos recursos simbólicos na cultura para responder à busca de sentido que se revela no espírito.

Se o desenvolvimento da dimensão espiritual é uma necessidade para qualquer ser humano, para o idoso ela se torna uma urgência, porque deverá encontrar um sentido para a nova etapa da existência em que os sustentáculos que antes amparavam o desenrolar da vida agora se fragilizam. O desafio é encontrar referenciais mais consistentes que possam fazer frente às manifestações da vulnerabilidade e à perspectiva da morte. Esta pode ser a causa porque os idosos em geral são pessoas com maior sensibilidade religiosa. Na senectude muitos reencontram certa prática religiosa ou buscam caminhos de espiritualização. (BIANCHI, 1991).

$\mathrm{Na}$ senescência o ser humano defronta-se com constantes 
antropológicas que a sensação de força e independência, experimentadas na idade jovem e adulta, podem fazer esquecer. $\mathrm{O}$ idoso expõe, manifesta e recorda a todos realidades humanas típicas como a apreensão do corpo próprio como expressão de si frente ao corpo biológico debilitado, maior consciência dos conteúdos da interioridade psíquica e da força da vivência do sentido ao nível do espírito. Na ancianidade capta-se com mais intensidade a importância dessas constantes para uma existência feliz e sadia, pois a velhice leva o ser humano a defrontar-se com seu corpo próprio, com sua interioridade psíquica e com seu horizonte de sentido para a existência, posto que não pode mais contar tanto com exterioridades que antes preenchiam e sustentavam a sua vida. Encontra-se diante da nudez da sua existência. Não é por nada que o ancião em culturas pré-modernas, era respeitado e tido como fonte de sabedoria e ensinamento.

\section{Questões Éticas da Senescência}

As questões éticas são fruto da esquizofrenia da situação do idoso na cultura atual: por um lado valorizado pela medicina que lhe fornece sempre maior longevidade; por outro, socialmente marginalizado, porque a sociedade não sabe o que fazer com os idosos sempre mais longevos. Não tendo lugar e papel para eles, o fato provoca no idoso uma sensação de inutilidade e obsolescência. Essa situação de isolamento agrava-se com a crescente dificuldade e falta de convivência intergeracional e chega ao paroxismo, em países do primeiro mundo, com a perda da consciência da solidariedade intergeracional. Não é apenas um conflito geracional de gostos culturais e valores morais; é um esvaziamento da interdependência familiar entre as gerações.

Os pais gastam o mínimo com seus filhos, empurrando-os precocemente para a independência, porque os filhos não terão cuidado dos pais idosos, fazendo que estes tenham que guardar dinheiro para uma boa provisão na velhice. Existe uma independização familiar em que cada um tem que se virar por si. Os laços afetivos na família tornam-se sempre mais frágeis, não sendo um sustento para momentos de dificuldade. Essa tendência leva a um progressivo isolamento e marginalização do idoso em asilos, longe do convívio intergeracional. Tudo isto é sinal de um modelo familiar em crise, de uma instituição em mutação. (ROUDINESCO, 2003).

A questão ética de fundo é sócio-cultural porque, por um lado, não 
existe lugar para o idoso na sociedade atual como acontecia em contextos sociais pré-modernos e, por outro, a própria cultura não fornece mais, como antes, referenciais simbólicos para ajudá-lo a enfrentar essa nova etapa da sua vida. O idoso é duplamente prejudicado. Por isso, é urgente apontar para exigências éticas que possam servir de pautas para políticas públicas para a senectude.

Os célebres princípios da bioética - autonomia, beneficência, nãomaleficência e justiça - (BEAUCHAMP; CHILDRESS, 2002) poderiam servir de caminho para apontar algumas diretrizes éticas para enfrentar a ancianidade a partir de diferentes perspectivas.

\subsection{Incentivo à Autonomia do Idoso}

A autonomia pode assumir dois enfoques: como tarefa ética para o idoso e como exigência moral para o cuidador. A senescência é, antes de mais nada, uma tarefa a ser assumida pelo próprio idoso. Como se preparar para viver com paz e serenidade a velhice, não se isolando nem deixando-se abater, mas reagindo com novas iniciativas e atividades? Isso significa, por um lado, saber conviver com as limitações e mudanças que a senectude impõe e, por outro, saber ressituar-se na vida de uma maneira autônoma. Alguns idosos assumem essa tarefa espontaneamente; outros precisam ser induzidos a esse aprendizado. O objetivo é conseguir que a pessoa, ao entrar na velhice, não entregue os pontos nem caia na dependência, mas tente manter o máximo de autonomia possível. Os clubes de terceira idade podem tornar-se um espaço para ajudar os idosos a assumir com consciência e autonomia seu processo de senescência, oferecendo referenciais simbólicos que reforcem a valorização como pessoa e a busca de um novo sentido para a vida.

A consciência de autonomia do idoso emerge e cresce quando é tratado pelos que o rodeiam como ser autônomo. Existe a tendência de infantilizar o idoso, tratando-o como um ser dependente que não sabe decidir o que é melhor para ele. Uma das importantes exigências éticas para o profissional ou familiar que toma conta do idoso é desenvolver nele a autonomia, incentivando, tanto quanto possível, a tomada de decisão e de iniciativa pessoais nas coisas referentes à sua higiene, saúde, ocupação, relações. 


\subsection{Promoção do Bem Estar do Idoso}

O princípio da beneficência aponta para a promoção do bem estar do idoso como um dever para os profissionais que trabalham com pessoas de idade avançada. Ele é, também, uma exigência de solidariedade para os familiares que convivem com algum idoso em sua casa. A questão central é o que significa prover benefícios ao idoso ou promover o seu bem estar. Tratase, apenas, de oferecer boas condições físicas de alojamento, comida, remédios, tratamento clínico?

Se o ser humano se caracteriza não só pela dimensão somática, mas também pela psíquica e espiritual, o processo de envelhecimento atinge e engloba as três dimensões. O bem estar do idoso deve contemplar igualmente e de uma maneira especial a sua interioridade psíquica e o seu horizonte espiritual. É necessário levar em consideração o universo dos afetos e das representações que preenchem o eu interior do idoso e ter presente os valores e os símbolos que dão sentido à sua existência.

Não adianta ter as melhores condições físicas de cama, comida e remédios se o idoso fica isolado e marginalizado, sofrendo de solidão e inutilidade, não se sentindo valorizado. Por isso é importante a presença afetiva de pessoas, principalmente familiares, impedindo que o processo de envelhecimento desenvolva tendências ao isolamento narcísico e ao ensimesmamento. Outra iniciativa importante é a reeducação do idoso por meio de terapias ocupacionais que ajudem a descobrir formas sadias de passar o tempo e a assumir atividades adequadas à idade e úteis ao grupo ou à sociedade. Trata-se de aspectos essenciais ao bem estar do idoso.

\subsection{Negligências e Maus-tratos contra o Idoso}

O princípio de não-maleficência contempla o dever de não provocar danos às pessoas que estão sob a responsabilidade de alguém. $\mathrm{O}$ idoso pode sofrer dano tanto pelo descuido da displicência quanto pela violência dos maus-tratos que podem ser físicos, psicológicos ou morais. (LAZARO DEL NOGAL; RIBERA CASADO, 2002).

As negligências e os maus-tratos na família são frutos de relações desgastadas, conflitos geracionais, problemas econômicos, produzindo stress no ambiente familiar e tornando pesada e difícil a tarefa de cuidar do idoso. Estes abusos contra o ancião tem um efeito destrutivo na sua qualidade de 
vida, porque sente-se desprezado e maltratado por palavras e gestos que atingem profundamente sua valorização afetiva. Nestes casos, a família e o idoso necessitam de uma terapia e ajuda para sair do impasse.

Nas instituições, os maus-tratos ocorrem quando os profissionais não estão preparados para o cuidado de idosos asilados, não são valorizados e insuficientes em número. Para superar essa situação é necessário, por um lado, existir uma inspeção e avaliação dos asilos por parte do poder público e, por outro, capacitar os profissionais, criando consciência sobre os direitos dos idosos e refletindo sobre normas fundamentais do seu cuidado. Para isso é necessário despertar a sociedade civil para os direitos do idoso e a denuncia dos seus abusos. Isso agora foi facilitado pela aprovação do Estatuto do Idoso. Alguns defendem a necessidade de criar Conselhos Tutelares dos direitos do idoso não só para acolher as denúncias, mas também encaminhálas para a Justiça, semelhantemente ao que existe para a defesa dos direitos das crianças e dos adolescentes. Pelo estatuto, o Conselho Municipal do Idoso deveria desempenhar essa função. O Estatuto oferece base jurídica para coibir e punir os abusos contra os direitos do idoso.

A tutela da criança e do adolescente e a do idoso tem especificidades próprias, pois a criança ainda não tem autonomia de decisão e o idoso está num processo de diminuição da capacidade de autonomia. Essa diminuição ou até ausência de autonomia seria a base jurídica para a tutela. Se os maustratos em asilos são mais fáceis de descobrir e superar, os que acontecem em ambiente familiar são difíceis de ser conhecidos e sanados, pois envolvem conotações afetivas que dificultam falar e dizer a verdade.

\subsection{Políticas Públicas de Defesa e Promoção dos Direitos do Idoso}

O princípio da justiça aponta para as obrigações das instituições do Estado e da Sociedade em relação à ancianidade. $\mathrm{O}$ bem estar do idoso não depende apenas de relações pessoais de cuidado por parte de familiares ou profissionais. Ele se baseia, muito mais, em políticas públicas que assegurem os direitos do idoso, criando condições para a promoção de sua autonomia, integração e participação efetiva na sociedade.

Esta foi a finalidade da Lei n. 8.842 de 4 janeiro de 1994, sancionada pelo Presidente da República (BRASIL, 1994), posteriormente completada pela Lei 4.227 de 13 de maio de 2002 que sanciona a criação do Conselho Nacional dos Direitos do Idoso (CNDI), encarregado de supervisionar e 
avaliar a Política Nacional do Idoso, estimular e assessorar a criação de Conselhos estaduais e municipais de defesa dos direitos do idoso e tornar efetiva a aplicação dos princípios e diretrizes da Lei n. 8.842.

No dia 24 de setembro de 2003 foi aprovado o Estatuto do Idoso pelo Congresso e logo depois sancionado pelo Presidente da República no dia 01 de outubro. Conta com 118 artigos que regulamentam os direitos das pessoas com idade igual ou superior a 60 anos e define as medidas de proteção. Tipifica os crimes contra os idosos e estabelece as punições. Proíbe a discriminação dos idosos nos planos de saúde. Determina o fornecimento gratuito de medicamentos pelo poder público. Garante 50\% de desconto nas atividades culturais e de lazer e a gratuidade nos transportes coletivos públicos. Define como crime a discriminação do idoso e a apropriação ou o desvio de bens, proventos, pensão ou qualquer outro rendimento do idoso.

A cultura jurídica brasileira é pródiga em criar belas leis, mas que permanecem, muitas vezes, inócuas por falta de aplicação. Por isso é necessário favorecer grupos de conscientização sobre os direitos do idoso e criar mecanismos de acompanhamento e avaliação do cumprimento do Estatuto. Os grupos de Terceira Idade e as Associações de aposentados e pensionistas são o lugar privilegiado para despertar a consciência e organizar a cobrança dos direitos.

\section{Conclusão}

A melhoria da situação do idoso depende mais de uma mudança de mentalidade cultural do que da criação de leis em defesa dos seus direitos. Essa melhoria não será efetiva enquanto não for superada a esquizofrenia cultural revelada pela contradição entre, por um lado, a crescente longevidade promovida pela medicina e, por outro, a manifesta inutilidade a que é reduzido o idoso na sociedade atual. $\mathrm{O}$ idoso interessa como consumidor, mas não existe para ele um papel social reconhecido. Para a mentalidade atual, ele não tem nada a contribuir publicamente para a sociedade. É reduzido à inatividade compulsória, vivendo da parca aposentadoria conferida pela sociedade para que permaneça parado. Essa inatividade marginaliza os idosos do convívio social. Assim, a velhice é uma realidade indecente e incômoda para a ideologia cultural que movimenta a mentalidade atual. Nisso consiste o problema ético de fundo da situação do idoso em nossos dias. 


\title{
CRITICAL VISION OF THE AGED SITUATION IN THE PRESENT CULTURAL CONTEXT
}

\begin{abstract}
The article presents a cultural critique of the mentality subjacent to the situation of the aged in the present post-modern context, analysis related to the Studies of A. Gorz about the Payed Work Society and of L. Sfez about the Perfect Health Ideology. Point out some anthropological aspects implied in the process of aging inspired on the philosophical Anthropolgy of H. C. de L. Vaz. Apply the traditional four bioethical principles - Autonomy, Beneficence, No-maleficence and Justice - to the Aged Care.

Keywords: Aged. Aging. Cultural Mentality. Post-modern Sociocultural Context. Aging Anthropolgy. Bioethics of Aging.
\end{abstract}

\section{REFERÊNCIAS}

BEAUVOIR, S. A Velhice: a realidade incômoda. 2. ed. São Paulo/Rio de Janeiro: Difel, 1976.

BEAUCHAMP, T. L.; CHILDRESS, J. F. Princípios de Ética Biomédica. Trad. Luciana Pudenzi. São Paulo: Loyola, 2002.

BIANCHI, E. C. Espiritualidade do Envelhecimento. Concilium, Petrópolis, t. 235, n. 3, p. 68-76, 1991.

BRASIL. Lei n. 8.842, de 4 de janeiro de 1994. Dispõe sobre a Política Nacional do Idoso; contempla a criação do Conselho Nacional do Idoso e dá outra providências. Diário Oficial da União, Brasília, v. 132, n. 3, p. 7779, Seção 1, pt. 1. 
CAILLÉ, A. Antropologia do Dom: o terceiro paradigma. Petrópolis: Vozes, 2002

GEBARA, I. Religião, Cultura e Envelhecimento: ponto de vista latinoamericano. Concilium, Petrópolis, t. 235, n. 3, p. 108-122, 1991.

GORZ, A. Misères du présent: richesse du possible. Paris: Galilée, 1997.

LAZARO DEL NOGAL, M.; RIBERA CASADO, J. M. El anciano: una víctima fácil para el abuso y el mal trato. In: FERRER, J. J.; MARTÍNEZ, J. L. (Ed.). Bioética: un diálogo plural. Madrid: Universidad Pontificia Comillas, 2002. P. 591-604.

LOLAS STEPKE, F. Sentido y significado de la vejez. In: . Bioética y Antropología Médica. Santiago, CL: Mediterraneo, 2000. P. 113-129.

MARTIN, G. R.; BAKER, G. T. Aging and the Aged: I. theories of aging and life extension. In: REICH, W. T. (Ed.). Encyclopedia of Bioethics. 2. ed. New York: Macmillan, 1995. v. 1. P. 85-87.

MATURANA, H.; VARELA, F. J. De Máquinas e Seres Vivos: autopoiese - a organização do vivo. Porto Alegre: Artes Médicas, 1997.

MAUSS, M. Essai sur le don. Paris: [s.n.], 1924.

MORAGAS, R. M. Gerontologia Social: envelhecimento e qualidade de vida. São Paulo: Paulinas, 1997.

PETRINI, M. Geriatria e Gerontologia: bioetica dell'anzianità. In: RUSSO, G. (Ed.). Bioetica Sociale. Torino: Elledici, 1999. P. 206-243.

POCHMANN, M. O Emprego na Globalização: a nova divisão internacional do trabalho e os caminhos que o Brasil escolheu. São Paulo: Bontempo, 2001. 
ROUDINESCO, E. A Família em Desordem. Rio de Janeiro: Jorge Zahar, 2003.

SFEZ, L. A Saúde Perfeita: crítica de uma nova utopia. São Paulo: Loyola, 1996.

TORRALBA i ROSELLÓ, F. Antropología del cuidar. Barcelona: Institut Borja de Bioética, 1998.

VAZ, H. C. L. Antropologia Filosófica. São Paulo: Loyola, 1991-1992. 2 V. 